\title{
Evaluating the potential of IP-10 and MCP-2 as biomarkers for the diagnosis of tuberculosis
}

\author{
M. Ruhwald*\#, T. Bodmer", C. Maier", M. Jepsen*, M.B. Haaland", \\ J. Eugen-OIsen ${ }^{\#}$ and P. Ravn ${ }^{\#,+}$ on behalf of TBNET
}

ABSTRACT: The aim of the present study was to evaluate the potential of diagnostic tests based on interferon- $\gamma$ inducible protein (IP)-10 and monocyte chemotactic protein (MCP)-2, and compare the performance with the QuantiFERON TB ${ }_{\mathbb{R}}$ Gold In-Tube (QFT-IT; Cellestis, Carnagie, Australia) test.

IP-10 and MCP-2 were determined in supernatants from whole blood stimulated with Mycobacterium tuberculosis-specific antigens. Samples were obtained from 80 patients with culture- and/or PCR-proven tuberculosis (TB), and 124 unexposed healthy controls: 86 high school students and 38 high school staff. IP-10 and MCP-2 test cut-offs were established based on receiver operating characteristic curve analysis.

TB patients produced significantly higher levels (median) of IP-10 (2158 pg $\mathrm{mL}^{-1}$ ) and MCP-2 (379 $\mathrm{pg} \cdot \mathrm{mL}^{-1}$ ) compared with interferon (IFN)- $\gamma\left(215 \mathrm{pg} \cdot \mathrm{mL}^{-1}\right)$. The QFT-IT, IP-10 and MCP-2 tests detected 81,83 and $71 \%$ of the TB patients; 0,3 and $0 \%$ of the high school students and 0,16 and $3 \%$ of the staff, respectively. Agreement between tests was high ( $>89 \%$ ). By combining IP-10 and IFN- $\gamma$ tests, the detection rate increased among TB patients to $90 \%$ without a significant increase in positive responders among the students.

In conclusion, interferon- $\gamma$ inducible protein-10 and monocyte chemotactic protein-2 responses to Mycobacterium tuberculosis-specific antigens could be used to diagnose infection. Combining interferon- $\gamma$ inducible protein-10 and interferon- $\gamma$ may be a simple approach to increase the detection rate of the Mycobacterium tuberculosis-specific in vitro tests.

KEYWORDS: Diagnosis, interferon- $\gamma$, interferon- $\gamma$ release assay, tuberculosis, whole blood

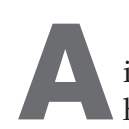
major breakthrough in the diagnosis of infection with Mycobacterium tuberculosis has been the development of in vitro assays that measure the production of interferon (IFN)- $\gamma$ in response to stimulation with $M$. tuberculosisspecific antigens (IFN- $\gamma$ release assay (IGRA) tests). The QuantiFERON TB ${ }_{\circledR}$ Gold In-Tube (QFT-IT; Cellestis, Carnagie, Australia) measures IFN- $\gamma$ responses by ELISA following incubation of whole blood with region of difference (RD) 1 and TB7.7 (Rv2654) antigens. The T-SPOT.TB ${ }_{\circledR}$ test (Oxford Immunotech, Abingdon, UK) measures the number of IFN- $\gamma$ responding cells by the enzyme-linked immunosorbent spot method following incubation of purified peripheral blood mononuclear cells (PBMCs) with RD1 antigens.
The IGRA tests have been extensively examined and current evidence suggests that both tests have a low false-positive rate $[1,2]$. Compared with the tuberculin skin test (TST), the IGRAs are better correlated with risk factors for infection with $M$. tuberculosis and do not give false-positive responses in bacille Calmette-Guerin (BCG)vaccinated individuals [3-5]. Additionally, in patients with active tuberculosis (TB) and especially in immunocompromised individuals the IGRAs are more sensitive than the TST [6-10]. However, there is a concern that the detection rate is still suboptimal and the tests perform with more indeterminate results, and a lower detection rate in patients with severe TB and immunocompromised patients [7, 9-12].

\section{AFFILIATIONS}

*Dept of Infectious Diseases,

${ }^{\#}$ Clinical Research Centre,

Copenhagen University, Hvidovre Hospital, Hvidovre,

+Dept of Medicine, Unit for Infectious Diseases, Copenhagen University, Herlev Hospital, Herlev, Denmark. "Institute for Infectious Diseases, University of Berne, Berne, Switzerland.

CORRESPONDENCE M. Ruhwald, Dept of Infectious Diseases 144, Copenhagen University, Hvidovre Hospital, 2650 Hvidovre, Denmark Fax: 4536323405 E-mail: mruhwald@mail.dk

Received:

April 122008

Accepted after revision:

July 242008

\section{SUPPORT STATEMENT}

This work was supported by the Danish Lung Association, the Lundbeck Foundation; the Augustinus Foundation (Copenhagen); and the Aase and Ejnar Danielsens Foundation (Lyngby, Denmark). M. Ruhwald is a PhD student holding a Scholarship from Copenhagen University, Capital Region, Denmark.

\section{STATEMENT OF INTEREST}

Statements of interest for $M$. Ruhwald, J. Eugen-OIsen and P. Ravn can be found at www.erj.ersjournals.com/misc/ statements.shtml 
The detection rate of IGRA could potentially be enhanced with the addition of further M. tuberculosis-specific antigens [13], by improving the incubation step [14-16] or by measuring alternative or additional biomarkers for IFN- $\gamma$ [16-20]. As part of the search for improved diagnostic measures, we have screened $>30$ potential biomarkers (as published previously [20] and observed in unpublished studies) and among those we have characterised IFN- $\gamma$ inducible protein (IP)-10 [20] and monocyte chemotactic protein (MCP)-2 as potential in vitro biomarkers for infection with $M$. tuberculosis.

Both IP-10 and MCP-2 are proinflammatory chemokines [21] which are expressed in inflamed tissues by resident and infiltrated cells (primarily monocyte/macrophages) after paracrine stimulation from T-cells by IFNs and other proinflammatory cytokines, or through innate mechanisms upon contact with viral, bacterial and fungal agents [22-27]. IP-10 is involved in trafficking monocytes and activated T-helper cell type 1 cells to inflamed foci through interaction with the CXC chemokine receptor (CXCR)3 [28]. MCP-2 is chemotactic for and activates many different cell types, including granulocytes and mononuclear cells, through various chemokine receptors including chemokine (C-C motif) receptor (CCR)1, CCR2B and CCR5 [21, 27]. Serum and pleural fluid IP-10 levels have been evaluated as biomarkers for diagnosis, prognosis and monitoring of treatment efficacy in inflammatory and infectious diseases, including TB. MCP-2 is less explored, but comparable properties have been described [20, 21, 29-38]. Both IP-10 and MCP-2 can be induced in monocytes and macrophages present in PBMC or whole blood by antigen and mitogen stimulation $[20,25,39]$.

The aims of the current study were to evaluate the potential of in vitro antigen-specific expression of IP-10 and MCP-2 for the diagnosis of $M$. tuberculosis infection and to evaluate whether IP-10 and MCP-2 could be used to improve the diagnosis of $M$. tuberculosis infection. The present study confirmed prior observations that IP-10 and MCP-2 could be used as a diagnostic biomarker in line with, or in addition to, IFN- $\gamma$.

\section{METHODS}

\section{Study population}

Material from 80 patients with active TB, 86 high school students and 38 high school staff were included. Patients with active TB based on positive culture and/or positive PCR were included from two centres in Europe: the Institute for Infectious Diseases of the University of Berne, Berne, Switzerland $(n=46)$ and Copenhagen University Hospital, Copenhagen, Denmark $(n=34)$. Clinical data was collected from patient files. Immunosuppression was classified according to LEE et al. [8]. Controls were included among students and staff at a high school in the greater Copenhagen area, Denmark (additional detail on the inclusion of controls is provided in the online supplementary material). The study protocol was approved by ethical committee of Copenhagen and Frederiksberg Municipal (KF 01-278477; Denmark) and by the ethical committee of Berne, Switzerland (KEK-BE 038/07).

\section{TST}

Controls and TB patients were skin tested using 2TU RT-23 tuberculin (Statens Serum Institute, Copenhagen, Denmark); $\geqslant 10 \mathrm{~mm}$ induration was considered positive.

\section{IFN- $\gamma$ determination by Quantiferon}

In total, $1 \mathrm{~mL}$ of whole blood was drawn into the three QFT-IT tubes (Cellestis; coated with saline (nil), M. tuberculosis-specific antigens or mitogen) and incubated for $18 \mathrm{~h}$. After centrifugation, IFN- $\gamma$ was measured in the supernatants by ELISA according to the manufacturer's instructions (Cellestis). IFN- $\gamma$ results are shown in $\mathrm{pg} \cdot \mathrm{mL}^{-1}$ to facilitate comparisons with the other biomarkers. One International unit of IFN- $\gamma$ corresponds to $50 \mathrm{pg} \cdot \mathrm{mL}^{-1}$ (NIBSC, Potters Bar, UK).

\section{IP-10 and MCP-2 determination}

On the same supernatants as above, IP-10 and MCP-2 were measured in duplicate by XMAP (Luminex Corporation, Austin, TX, USA) technology as previously described [20]. Samples were diluted 1:3 in assay diluent in order to optimise the expected IP-10 concentrations in the antigen tube to the range of the standard curve. Levels above the upper limit of quantification were assigned the upper limit $\left(19,920 \mathrm{pg} \cdot \mathrm{mL}^{-1}\right.$ for IP-10 and $8,820 \mathrm{pg} \cdot \mathrm{mL}^{-1}$ for MCP-2). The lower level of quantification was $20 \mathrm{pg} \cdot \mathrm{mL}^{-1}$ for both biomarkers.

\section{Data analysis}

Data were analysed using SAS 9.1.3 (SAS institute, Cary, NC, USA) and R (R Development Core Team, Vienna, Austria). Variables with normal distribution were described using mean \pm SD and means were compared using a paired t-test. Variables that were not normally distributed were compared across and within groups using nonparametic tests (KruskalWallis and Wilcoxon signed-rank test). Biomarker correlation was assessed using the Spearman's rank test. The antigendependent and the mitogen-induced biomarker production were measured by subtracting the concentration measured in the nil tube from the concentration measured in the antigen and mitogen tube, respectively.

The diagnostic performance of the antigen-dependent biomarker values per se was compared using the receiver operating characteristic curve (ROC) analysis and the area under the curve (AUC), as suggested by HANLEY and MCNeIL [40]. Cutoffs for antigen-dependent IP-10 and MCP-2 were estimated at various sensitivities and specificities and at the maximum Youden's index (YI), i.e. sensitivity + specificity - 1 [41].

The following criteria were defined for potential diagnostic IP10 and MCP-2 tests: positive if the antigen-dependent biomarker production was above the selected cut-off; negative if the antigen-dependent biomarker production was below the selected cut-off and not indeterminate; and indeterminate if the antigen-dependent response was negative and the mitogeninduced response was $<200 \mathrm{pg} \cdot \mathrm{mL}^{-1}$ for the IP-10 test and $150 \mathrm{pg} \cdot \mathrm{mL}^{-1}$ for the MCP-2 test. These cut-offs were arbitrarily chosen. Test concordance was assessed using $\kappa$ statistics. The McNemar's test was applied when comparing marginal homogeneity, detection and false-positive rate. All tests were two-sided and $p$-values $<0.05$ were considered significant.

\section{RESULTS}

\section{Study population}

Plasma samples from 80 patients with active TB and 124 (86 high school students and 38 high school staff) controls were included (table 1). The TB patients were significantly older than the students and ethnically more diverse. In total, 50\% 
TABLE 1 Demographic and clinical characteristics

\begin{tabular}{|c|c|c|c|}
\hline & Students & Staff & TB patients \\
\hline Subjects $n$ & 86 & 38 & 80 \\
\hline Age yrs & $17.6 \pm 1.3$ & $54.5 \pm 8.5$ & $46.4 \pm 19.3$ \\
\hline Males $\mathbf{n}$ & $23(27)$ & $13(34)$ & $39(49)$ \\
\hline \multicolumn{4}{|l|}{ Ethnicity } \\
\hline Europe/North America & $86(100)$ & $38(100)$ & $40(50)$ \\
\hline Africa & $0(0)$ & $0(0)$ & $18(23)$ \\
\hline Asia & $0(0)$ & $0(0)$ & $21(26)$ \\
\hline Other (Tahiti) & $0(0)$ & $0(0)$ & $1(1)$ \\
\hline \multicolumn{4}{|l|}{ Prior TB treatment/disease } \\
\hline No & $86(100)$ & $38(100)$ & $8(10)$ \\
\hline Yes & $0(0)$ & $0(0)$ & $2(3)$ \\
\hline Unknown & $0(0)$ & $0(0)$ & $70(87)$ \\
\hline \multicolumn{4}{|l|}{$\begin{array}{l}>2 \text { months in TB } \\
\text { endemic country }\end{array}$} \\
\hline No & $86(100)$ & $38(100)$ & $6(8)$ \\
\hline Yes & $0(0)$ & $0(0)$ & $45(68)$ \\
\hline Unknown & $0(0)$ & $0(0)$ & $20(25)$ \\
\hline \multicolumn{4}{|l|}{ TB type } \\
\hline Pulmonary & & & $42(53)$ \\
\hline Extrapulmonary & & & $32(40)$ \\
\hline $\begin{array}{l}\text { Pulmonary and } \\
\text { extrapulmonary }\end{array}$ & & & $6(8)$ \\
\hline \multicolumn{4}{|l|}{ Co-morbidity } \\
\hline HIVpositive $n / n$ tested & $0 / 0(0)$ & $0 / 0(0)$ & $10 / 56(18)$ \\
\hline $\begin{array}{l}\text { Other immunosuppressive } \\
\text { treatment or condition }\end{array}$ & $0(0)$ & $0(0)$ & $8(10)$ \\
\hline TST $>10 \mathrm{~mm} \mathrm{n} / \mathrm{n}$ done & $0 / 80(0)$ & $8 / 38(21)$ & $9 / 12(75)$ \\
\hline \multicolumn{4}{|l|}{ PCR } \\
\hline Positive & & & $60(75)$ \\
\hline Negative & & & $12(15)$ \\
\hline Not done & & & $8(10)$ \\
\hline \multicolumn{4}{|l|}{ Microscopy } \\
\hline Positive & & & $44(55)$ \\
\hline Negative & & & $26(33)$ \\
\hline Not done & & & $10(13)$ \\
\hline \multicolumn{4}{|l|}{ Culture } \\
\hline Positive & & & $68(85)$ \\
\hline Negative & & & $8(10)$ \\
\hline Not done & & & $4(5)$ \\
\hline
\end{tabular}

Data are presented as $n(\%)$ and mean $\pm \mathrm{SD}$, unless otherwise stated. TB: tuberculosis; TST: tuberculin skin test.

were born in a high TB endemic country, and $62 \%$ had spent $>2$ months in a TB endemic country, $48 \%$ had extrapulmonary $\mathrm{TB}, 13 \%$ were HIV positive and $10 \%$ were considered relatively immunosuppressed (treated with $>15 \mathrm{mg} \cdot$ day $^{-1}$ prednisolone $(n=4)$, post-transplantation chemotherapy $(n=1)$, haematologic malignancy $(\mathrm{n}=1)$ and chronic renal failure $(\mathrm{n}=2))$. The students who were BCG unvaccinated were predominantly female, ethnic Danes with no history of TB exposure. All staff had been BCG vaccinated.

\section{TST and QFT-IT results}

TST results were available for $15 \%$ (12 out of 80 ) of the TB patients, of whom $75 \%$ were positive. All controls underwent

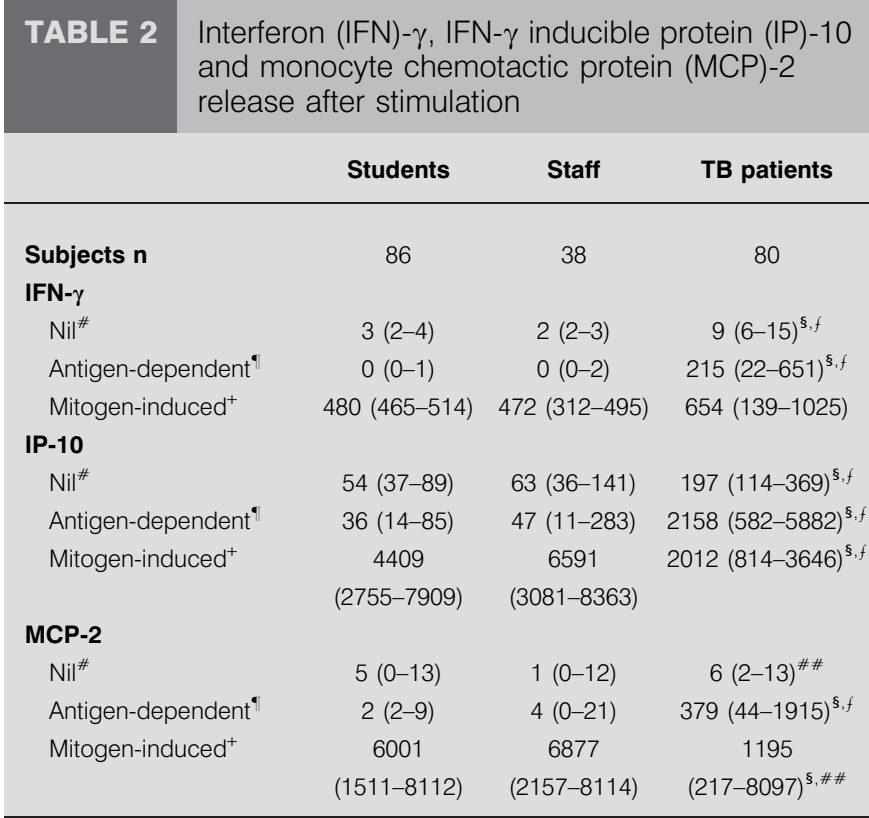

Data are presented as median concentration in $\mathrm{pg} \cdot \mathrm{mL}^{-1}$ (interquartile range), unless otherwise stated. TB: tuberculosis. ${ }^{\#}$ : unstimulated; ": Mycobacterium tuberculosis antigen-stimulated subtracted nil; $^{+}$: phytohaemaglutinin stimulated subtracted nil; ${ }^{\text {s: }} p<0.0001$ versus students; ${ }^{f}: p<0.0001$ versus staff; \#\#: $p<0.005$ versus staff (Kruskal-Wallis test)

TST, 21\% (eight out of 38) of staff but none of the 86 students were TST positive. Among the 80 patients, 65 (81\%) were QFTIT positive, and four $(5 \%)$ were QFT-IT indeterminate, due to low mitogen response. All controls were QFT-IT negative and none were indeterminate.

\section{Biomarker levels}

TB patients produced significantly higher antigen-dependent levels of all biomarkers compared with the controls, whereas the mitogen-induced IP-10 and MCP-2 levels generally were lower (table 2). The TB patients showed significantly higher levels of IFN- $\gamma$ and IP-10 in the nil samples compared with both students and staff. There were no significant differences between students and staff for any of the biomarkers $(p>0.07)$. In figure 1 the individual measurements of antigen- and mitogeninduced responses are shown. TB patients produced IP-10 and MCP-2 in 16.8 (interquartile range 5.2-36.0) and $2.7(0.6-6.2)-$ fold higher magnitude compared with IFN- $\gamma(\mathrm{p}<0.0001)$. There was no significant difference in any of the biomarker levels when comparing the relatively immunosuppressed and HIV infected with the TB patients without comorbidity.

\section{Correlation}

A high correlation was observed in the antigen-dependent responses between IFN- $\gamma$ and IP-10 $(r=0.81)$ and between IFN- $\gamma$ and MCP-2 $(r=0.72 ; p<0.0001$; Spearman). The mitogen-induced levels of IFN- $\gamma$ correlated less with IP-10 $(r=0.30)$ and MCP-2 $(\mathrm{r}=0.41)$, although it was still significant ( $\mathrm{p}<0.0001$; Spearman).

\section{Diagnostic performance of IP-10 and MCP-2}

The diagnostic performance of the biomarkers was compared using the ROC curve analysis. Students and TB patients were 

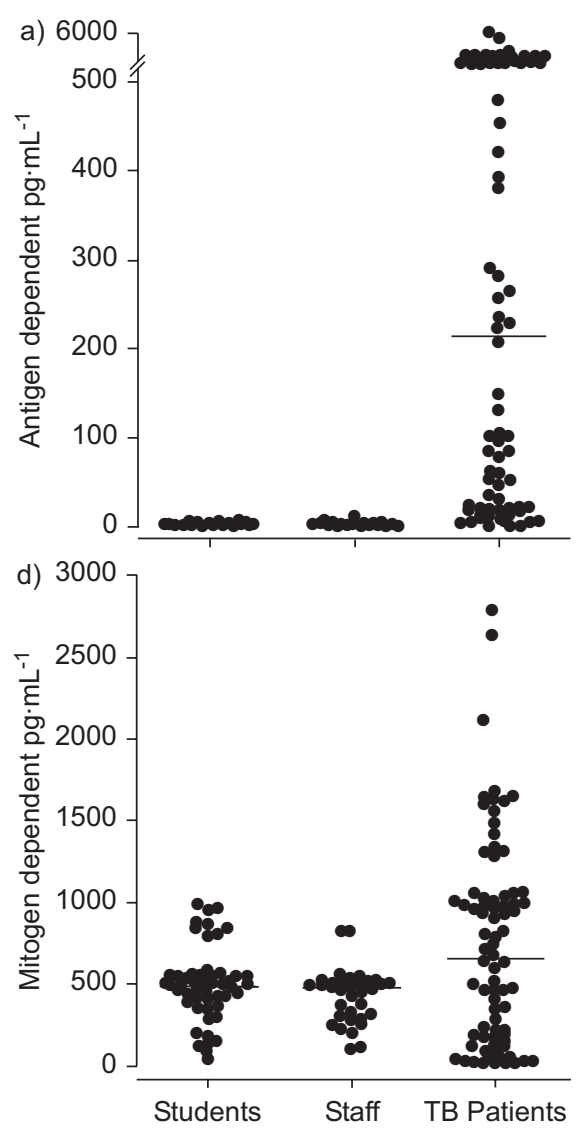
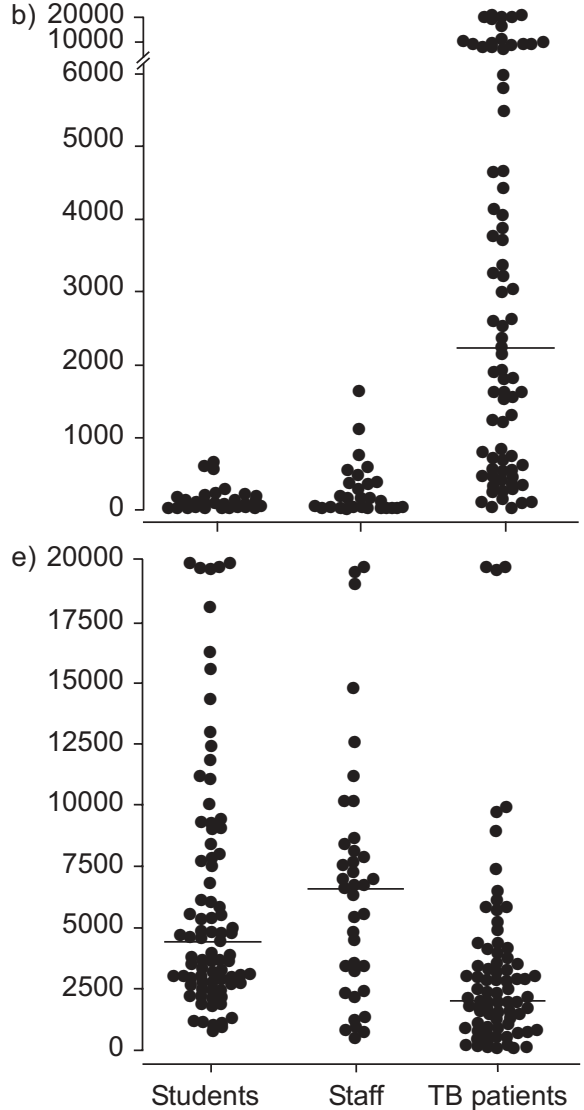
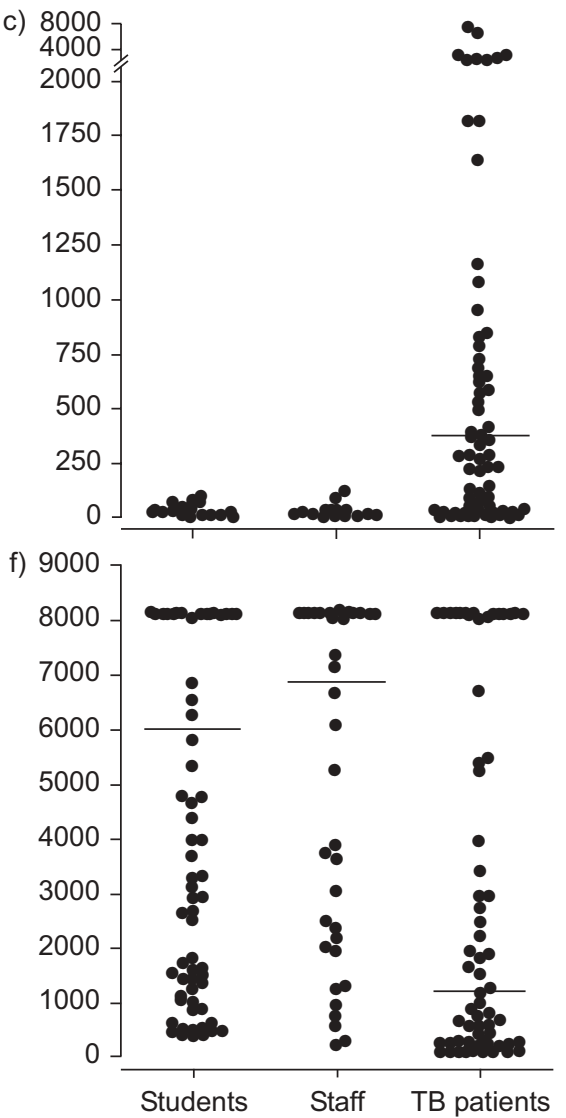

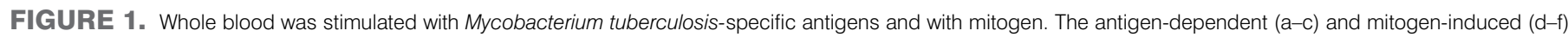

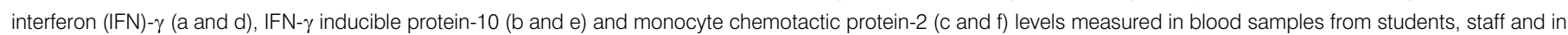
patients with active tuberculosis (TB).

: an individual; : median levels

used as gold standard for noninfected and infected (fig. 2). There was no statistically significant difference between the AUC of IFN- $\gamma, 0.98$ compared with IP-10, $0.95(p=0.1)$, but the AUC of MCP-2 (0.89) was significantly lower compared with IFN- $\gamma$ and IP-10 $(\mathrm{p}<0.04)$.

\section{Diagnostic tests based on IP-10 or MCP-2}

Like IFN- $\gamma$, IP-10 and MCP-2, responses to mitogen and antigen are inherently continuous; consequently, diagnostic test algorithms were used to convert them into positive, negative and indeterminate test results. The cut-offs for positive tests were estimated using ROC curve analysis on the antigen-dependent values (fig. 2). For IP-10, the maximum YI was achieved at the cut-off $237 \mathrm{pg} \cdot \mathrm{mL}^{-1}$ (detection rate $90 \%$, false-positive rate $5 \%$ ). Ideal false-positive rate $(0 \%)$ was found using a higher cut-off $\left(673 \mathrm{pg} \cdot \mathrm{mL}^{-1}\right)$ with a lower detection rate $(74 \%)$. It is likely that these two cut-offs represent the extremes in a range of potential cut-offs in the test. Since the aim of the current study was to explore the cut-off with high detection rate and low false-positive rate that was applicable in a clinical setting, a cut-off at $455 \mathrm{pg} \cdot \mathrm{mL}^{-1}$ (detection rate $80 \%$, falsepositive rate $3 \%$ ) halfway between these two extremes was pragmatically selected for the evaluation of a potential IP-10 test. In addition, the performance of an IP-10 test based on the marginal IP-10 cut-offs (IP-10 test $237 \mathrm{pg} \cdot \mathrm{mL}^{-1}$ and IP-10 test $673 \mathrm{pg} \cdot \mathrm{mL}^{-1}$ ) was explored. For MCP-2 the cut-off was selected at maximum YI $95.7 \mathrm{pg} \cdot \mathrm{mL}^{-1}$ (detection rate $71 \%$, false-positive rate $0 \%$ ). There was no apparent alternative MCP-2 cut-off with an increasing detection rate, as the trade off in falsepositive rate was too high (fig. 2). Maximum YI for IFN- $\gamma$ was $4.0 \mathrm{pg} \cdot \mathrm{mL}^{-1}$ (detection rate $95 \%$, false-positive rate $1 \%$ ), whereas the cut-off recommended by the manufacturer is $17.5 \mathrm{pg} \cdot \mathrm{mL}^{-1}$ (detection rate $81 \%$, false-positive rate $0 \%$ ).

\section{Test results and concordance}

The rate of positive, negative and indeterminate responders was calculated using the IP-10 and MCP-2 test algorithms and the results were compared with the QFT-IT test (table 3).

The rates of positive responders among TB patients were $81 \%$ (65 out of 80 ) for the QFT-IT, and 83\% (66 out of 80 ) for the IP-10 test $455 \mathrm{pg} \cdot \mathrm{mL}^{-1}$. When excluding the indeterminate responders the detection rate increased to $86 \%$ (65 out of 76 ) and $89 \%$ (66 out of 74). The IP-10 test $455 \mathrm{pg} \cdot \mathrm{mL}^{-1}$ had a higher proportion of positive responders among all controls $7 \%$ (nine out of 124), with $3 \%$ (three out of 86 ) positive students and $16 \%$ (six out of 38) positive staff $(p<0.02)$. For individual patient characteristics see online supplementary material. There was no association with immunosuppression and risk of false-negative test result for any of the tests $(\mathrm{p}>0.33)$. There was a very high agreement between the QFT-IT and the MCP-2 test (93\%; $\kappa 0.84)$; and the QFT-IT and the IP-10 test $455 \mathrm{pg} \cdot \mathrm{mL}^{-1}(89 \%$; $\kappa$ 0.77; $\mathrm{p}<0.0001$; 


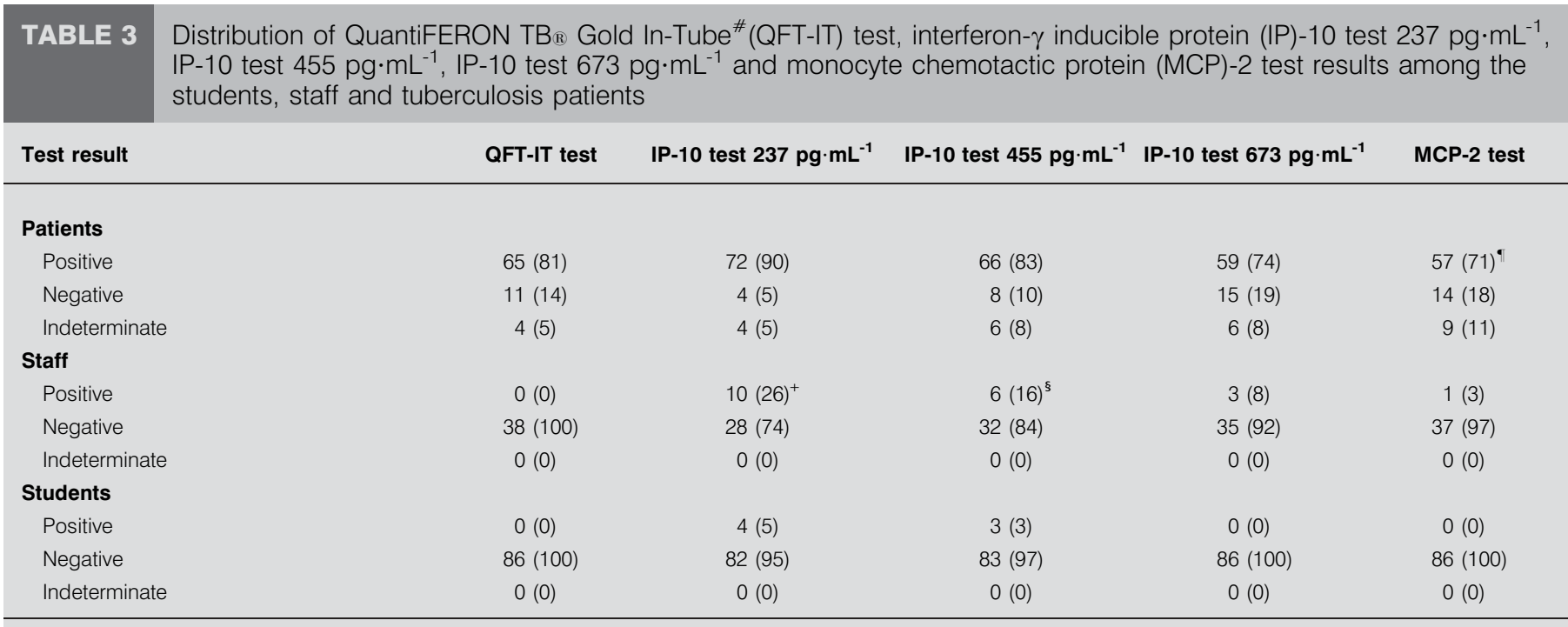

Data are presented as $n(\%) .{ }^{*}$ : manufactured by Cellestis, Carnagie, Australia. ": statistically different detection rate compared with QFT-IT ( $\left.p<0.04\right) ;{ }^{+}:$statistically different rate of positive responders (approximation of false-positive rate) compared with QFT-IT $(p<0.002)$; ${ }^{\$}$ : statistically different rate of positive responders (approximation of false-positive rate) compared with QFT-IT $(p<0.02)$

see online supplementary material). The three tests agreed in $175(86 \%)$ out of 204 of all samples examined (data not shown).

\section{Increasing detection rate using marginal cut-offs and combining biomarkers}

The rate of positive responders was compared using the lower cut-offs for IP-10 and IFN- $\gamma$. The detection rate for the IP-10 test

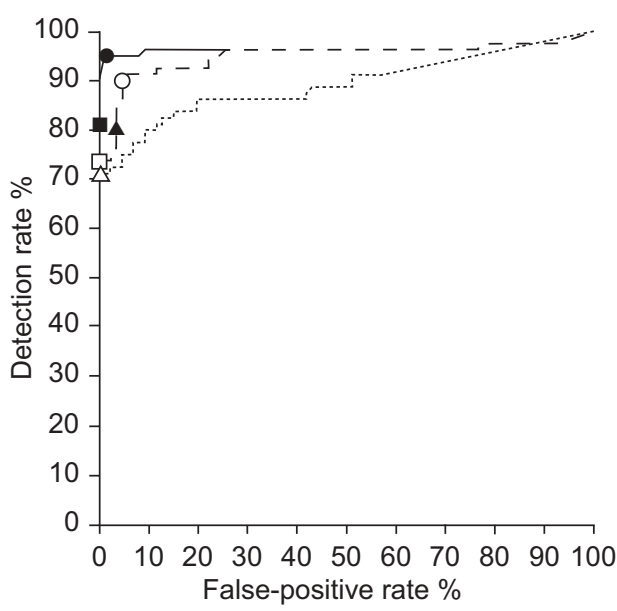

FIGURE 2. Whole blood was stimulated with Mycobacterium tuberculosisspecific antigens or saline. The diagnostic potential of interferon (IFN)- $\gamma$, IFN- $\gamma$ inducible protein (IP)-10 and monocyte chemotactic protein (MCP)-2 was determined by receiver operating characteristic curve analysis using antigendependent values. Students were used as gold standard for noninfected; tuberculosis patients were used as gold standard for infected. - : maximum Youden's index (YI) for IFN- $\gamma\left(4 \mathrm{pg} \cdot \mathrm{mL}^{-1}\right) ; \triangle$ : maximum $\mathrm{YI}$ for MCP-2 $\left(97 \mathrm{pg} \cdot \mathrm{mL}^{-1}\right)$; - : cut-off applied in the QuantiFERON In-Tube test (Cellestis, Carnagie, Australia; $17.5 \mathrm{pg} \cdot \mathrm{mL}^{-1}$ ); $\mathrm{O}$ : maximum $\mathrm{YI}$ for $\mathrm{IP}-10$ test, used as cut-off for the IP-10 test (237 pg. $\left.\mathrm{mL}^{-1}\right)$; $\square$ : cut-off for the IP-10 test $\left(673 \mathrm{pg} \cdot \mathrm{mL}^{-1}\right) ; \mathbf{\Lambda}$ : selected pragmatic cut-off for the IP-10 test $\left(455 \mathrm{pg} \cdot \mathrm{mL}^{-1}\right)$. ——: IFN- $\gamma_{;}----$: IP-10; …: MCP-2.
$237 \mathrm{pg} \cdot \mathrm{mL}^{-1}$ increased to $90 \%$ (72 out of 80 ), $95 \%$ (74 out of 75 ; excluding indeterminate) and to $26 \%$ (10 out of 38 ) among staff, but only to $5 \%$ (four out of 86 ) among students. With the IP-10 test $673 \mathrm{pg} \cdot \mathrm{mL}^{-1}$ the detection rate was lower $74 \%$ (59 out of 80$),(80 \%$ (59 out of 74 ) excluding indeterminate), and the rate of positive responders was $8 \%$ (three out of 38) among staff and $0 \%$ (none out of 86 ) among controls (clinical data are provided in online supplementary material). Using the cut-off point for IFN- $\gamma$ identified on the ROC curve as optimal $\left(4 \mathrm{pg} \cdot \mathrm{mL}^{-1}\right)$, the proportion of positive responders significantly increased from $81 \%$ (65 out of 80 ) to $95 \%$ (76 out of $80 ; 96 \%$ (76 out of 79) excluding indeterminate responders) and the positive rate among controls remained low at $2 \%$ (three out of 124).

Next, the authors evaluated if a combined biomarker approach could increase the detection rate without compromising specificity. A patient was classified as positive if at least one of two tests were positive and found that the combination of IP-10 test $455 \mathrm{pg} \cdot \mathrm{mL}^{-1}$ and QFT-IT increased the detection rate

\begin{tabular}{|c|c|c|c|c|}
\hline TABLE 4 & $\begin{array}{l}\text { ad-to-hea } \\
\text { erculosis } \\
\text { ld In-Tube } \\
\text { ucible prc }\end{array}$ & $\begin{array}{l}\text { omparis } \\
\text { ients for } \\
\text { QFT-IT) t } \\
\text { (IP)-10 }\end{array}$ & $\begin{array}{l}\text { of test result } \\
\text { QuantiFER } \\
\text { and interferc } \\
455 \mathrm{pg} \cdot \mathrm{mL}\end{array}$ & $\begin{array}{l}\text { nong } \\
T_{B}\end{array}$ \\
\hline \multirow{2}{*}{$\begin{array}{l}\text { IP-10 test } \\
455 \mathrm{pg} \cdot \mathrm{mL}^{-1}\end{array}$} & \multicolumn{3}{|c|}{ QFT-IT } & \multirow[t]{2}{*}{ Total } \\
\hline & Negative & Positive & Indeterminate & \\
\hline Negative & 5 & 2 & 1 & 8 \\
\hline Positive & 6 & 59 & 1 & 66 \\
\hline Indeterminate & 0 & 4 & 2 & 6 \\
\hline Total & 11 & 65 & 4 & 80 \\
\hline
\end{tabular}

Agreement 83\%; $\kappa=0.44 .{ }^{\#}$ : manufactured by Cellestis, Carnagie, Australia 


\begin{tabular}{|c|c|c|c|c|}
\hline TABLE 5 & $\begin{array}{l}\text { ad-to-hea } \\
\text { erculosis } \\
\text { ld In-Tube } \\
\text { ducible pro }\end{array}$ & $\begin{array}{l}\text { omparis } \\
\text { tients for } \\
\text { QFT-IT) } \\
\text { n (IP)-10 }\end{array}$ & $\begin{array}{l}\text { of test results } \\
\text { e QuantiFERC } \\
\text { and interfero } \\
\text { st } 673 \mathrm{pg} \cdot \mathrm{mL}^{-}\end{array}$ & $\begin{array}{l}\text { nong } \\
\text { TB }\end{array}$ \\
\hline \multirow{2}{*}{$\begin{array}{l}\text { IP-10 test } \\
673 \mathrm{pg} \cdot \mathrm{mL}^{-1}\end{array}$} & \multicolumn{3}{|c|}{ QFT-IT } & \multirow[t]{2}{*}{ Total } \\
\hline & Negative & Positive & Indeterminate & \\
\hline Negative & 7 & 7 & 1 & 15 \\
\hline Positive & 4 & 54 & 1 & 59 \\
\hline Indeterminate & 0 & 4 & 2 & 6 \\
\hline Total & 11 & 65 & 4 & 80 \\
\hline
\end{tabular}

Agreement $89 \% ; \kappa=0.43 .{ }^{*}$ : manufactured by Cellestis, Carnagie, Australia.

to $90 \%$ (72 out of $80 ; \mathrm{p}<0.009 ; 92 \%$ (72 out of 78 ) excluding indeterminate responders; table 4$)$. The positivity rate among controls remained low $7 \%$ (nine out of 124). Interestingly, when combining the IP-10 test $673 \mathrm{pg} \cdot \mathrm{mL}^{-1}$ with the QFT-IT, the detection rate increased significantly to $88 \%$ (70 out of 80 ; $\mathrm{p}<0.03 ; 90 \%$ when excluding indeterminate responders; table 5), with a positive rate among the controls of $2 \%$ (three out of 124). Combining MCP-2 with the QFT-IT or the IP-10 test did not increase the detection rate significantly $(p=0.08$ and $\mathrm{p}=0.3$, respectively; table 6 ).

\section{DISCUSSION}

The current study evaluated the potential of using antigenspecific IP-10 and MCP-2 expression for in vitro diagnosis of $M$. tuberculosis infection. After stimulation of whole blood with $M$. tuberculosis-specific antigens, IP-10 and MCP-2 were expressed by infected individuals and in significantly higher amounts than IFN- $\gamma$. IP-10 and MCP-2 tests were established, which performed with excellent concordance with the QFT-IT. By combining the results of IP- 10 and IFN- $\gamma$, it was possible to increase the detection rates among TB patients $81-90 \%$ without a significant increase in positive responders among the students.

There is a demand for new diagnostic tests for TB with improved detection rates and which are simpler to perform, i.e. with a bedside readout similar to that of the lateral flow

\begin{tabular}{lcccc} 
TABLE 6 & $\begin{array}{l}\text { Head-to-head comparison of test results among } \\
\text { TB patients QuantiFERON TB } \\
\text { (QFT-IT) test with the monocyte chemotactic } \\
\text { protein (MCP)-2 test } \\
\text { MCP-2 test }\end{array}$ & \multicolumn{4}{c}{ QFT-IT } & Total \\
\cline { 2 - 4 } & Negative & Positive & Indeterminate & \\
\cline { 2 - 4 } Negative & 8 & 6 & 0 & 14 \\
Positive & 3 & 54 & 0 & 57 \\
Indeterminate & 0 & 5 & 4 & 9 \\
Total & 11 & 65 & 4 & 80 \\
\hline
\end{tabular}

Agreement $83 \% ; \kappa=0.55$. \#: manufactured by Cellestis, Carnagie, Australia. technique as used in the rapid tests for malaria and HIV [42, 43]. Several new promising technologies for active TB have emerged [44] but since the introduction of the RD1 antigenbased IGRAs in 2000, no major breakthroughs have been made to improve the diagnostic tools for latent infection $[8,42,43]$.

Alternative biomarkers expressed in higher amounts than IFN- $\gamma$ could improve the detection rate of the in vitro tests for $M$. tuberculosis infection, but so far no alternatives have shown to have similar or superior potential compared with IFN- $\gamma$. RD1-antigen stimulated expression of interleukin (IL)-2, IL-4, IL-10, macrophage inflammatory protein- $1 \alpha$, MCP-1, monokine induced by IFN- $\gamma$, IL- 8 and the cell activation surfacemarker CD40L have been examined, but responses were either inconsistent, difficult to measure, or lower compared with IFN- $\gamma$ [16-20].

IGRA tests are primarily tools developed to diagnose latent $M$. tuberculosis infection [1], but due to the lack of a gold standard for latent $M$. tuberculosis infection, active TB is often used as a model to evaluate test performance [45]. QFT-IT is a robust IGRA, and several large studies have documented a high detection rate in TB patients without comorbidity and very low false-positive rate in healthy individuals from low endemic regions [1]. The performance of the QFT-IT in the present study was comparable with other studies on similar material $[1,45,46]$. The IP-10 test $455 \mathrm{pg} \cdot \mathrm{mL}^{-1}$ and the MCP-2 test performed comparably to the QFT-IT and the three tests agreed in $89 \%$ of all samples examined.

The range of potential IP-10 cut-offs with high detection rate and low false-positive rate led the current authors to evaluate test performance at different cut-offs. In the range 237$673 \mathrm{pg} \cdot \mathrm{mL}^{-1}$, detection rates were obtained ranging $74-90 \%$ among TB patients, with positivity rates in students $0-6 \%$ and staff $8-26 \%$. Interestingly, the majority of controls that had a positive reaction with the IP-10 test were staff and aged $>50 \mathrm{yrs}$. It is well known that there is an increasing risk of $M$. tuberculosis exposure with age and the positive responses in these individuals could possibly reflect prior M. tuberculosis exposure. However, the current study was not designed to evaluate latent TB infection and studies in persons with known exposure to patients with active $\mathrm{TB}$ are needed to test this hypothesis.

Applying the $4 \mathrm{pg} \cdot \mathrm{mL}^{-1}\left(0.08 \mathrm{IU} \cdot \mathrm{mL}^{-1}\right)$ cut-off for IFN- $\gamma$ in the present study population resulted in an increase in detection rate to $96 \%$ with only minor increase in false-positive rate to $2 \%$. The calculations support the increasing number of papers discussing whether the QFT-IT cut-off could be lowered to increase QFT-IT performance [8, 47, 48], it is however not sufficiently explored if reduced cut-off for the QFT-IT will compromise the very low false-positive rate seen in most studies [1] and whether these very low IFN- $\gamma$ concentrations can be reliably reproduced with serial or repeated testing $[9,49]$.

The most striking finding of the study was that the detection rate was increased using a combined biomarker approach. Depending on the IP-10 cut-off detection rate increased from 81 to $88 \%$ or $90 \%$, with only minimal influence on the rate of false-positive controls. This combined biomarker approach would be an easy way to improve the already existing tests. 
Interestingly the same adjunct effects were not seen on QFT-IT combination with the MCP-2 test.

The present authors have demonstrated the performance of IP10 and MCP-2 in an exploratory study using "the sickest of the sick and the wellest of the well" [50]. The limitation of this approach is the risk of over-optimistic cut-offs and overestimated test accuracy, and the present study design does not allow the determination of the sensitivity, specificity, positive and negative predictive values or likelihood ratio of the new tests. These qualities need to be determined in another population.

In the present study the xMAP assay was used, an assay which has not been optimised for this specific purpose. Further optimisation of the readout platform could result in improved test performance and the optimal cut-off for an IP10 test needs to be confirmed in clinically relevant challenge studies [50]. Such studies should focus on the performance of the new tests in patients with other inflammatory or infectious disorders, and in latently infected individuals. Furthermore neither the IGRA nor the IP-10 or MCP-2 test, at this stage, solves the issue of active TB versus latent TB infection, e.g. diagnosing active TB in patients with clinical suspicion of TB within a population with a high prevalence of latent $\mathrm{TB}$ infection.

An algorithm for the IP-10 and MCP-2 tests was used that was similar to the algorithm developed for IFN- $\gamma$. The optimal algorithm for an IP-10 or MCP-2 based test, however, may differ from that of IFN- $\gamma$.

In conclusion, there is a need for added sensitivity when screening high-risk populations, e.g. immunocompromised patients and for the diagnosis of patients with active tuberculosis. The present data suggests that monocyte chemotactic protein- 2 and, especially, interferon- $\gamma$ inducible protein10 could be promising new biomarkers, as they are produced antigen specifically in high amounts by tuberculosis patients and not by controls. Most interestingly, the present authors have demonstrated that by simply combining the measurement of interferon- $\gamma$ inducible protein-10 and interferon- $\gamma$ test accuracy improved significantly.

\section{ACKNOWLEDGEMENTS}

The authors would like to thank the colleagues who assisted in collecting blood samples; B. Søborg (Statens Serum Institute, Copenhagen, Denmark) for supervising the analysis of the Quantiferon tubes; L. Hansen, A. Stausgaard and A.L. Sørensen (all Clinical Research Centre, Copenhagen University, Hvidovre Hospital, Hvidovre, Denmark) for technical assistance; and K. Larsen (Clinical Research Centre, Copenhagen University, Hvidovre Hospital) for statistical support and for programming the Hanley-McNeil test in R.

\section{REFERENCES}

1 Menzies D, Pai M, Comstock G. Meta-analysis: new tests for the diagnosis of latent tuberculosis infection: areas of uncertainty and recommendations for research. Ann Intern Med 2007; 146: 340-354.
2 Soborg B, Andersen AB, Larsen HK, et al. Detecting a low prevalence of latent tuberculosis among health care workers in Denmark detected by M. tuberculosis specific IFN- $\gamma$ whole-blood test. Scand J Infect Dis 2007; 39: 554-559.

3 Brock I, Weldingh K, Lillebaek T, Follmann F, Andersen P. Comparison of tuberculin skin test and new specific blood test in tuberculosis contacts. Am J Respir Crit Care Med 2004; 170: 65-69.

4 Hill PC, Brookes RH, Adetifa IMO, et al. Comparison of enzyme-linked immunospot assay and tuberculin skin test in healthy children exposed to Mycobacterium tuberculosis. Paediatrics 2006; 117: 1542-1548.

5 Nakaoka H, Lawson L, Squire SB, et al. Risk for tuberculosis among children. Emerg Infect Dis 2006; 12: 1383-1388.

6 Ferrara G, Losi M, Meacci M, et al. Routine hospital use of a new commercial whole blood interferon- $\gamma$ assay for the diagnosis of tuberculosis infection. Am J Respir Crit Care Med 2005; 172: 631-635.

7 Ferrara G, Losi M, D'Amico R, et al. Use in routine clinical practice of two commercial blood tests for diagnosis of infection with Mycobacterium tuberculosis: a prospective study. Lancet 2006; 367: 1328-1324.

8 Lee JY, Choi HJ, Park IN, et al. Comparison of two commercial interferon- $\gamma$ assays for diagnosing Mycobacterium tuberculosis infection. Eur Respir J 2006; 28: 24-30.

9 Luetkemeyer AF, Charlebois ED, Flores LL, et al. Comparison of an interferon- $\gamma$ release assay to tuberculin skin testing in HIV-infected individuals. Am J Respir Crit Care Med 2007; 175: 737-742.

10 Kobashi Y, Mouri K, Yagi S, et al. Usefulness of the QuantiFERON TB-2G test for the differential diagnosis of pulmonary tuberculosis. Intern Med 2008; 47: 237-243.

11 Brock I, Ruhwald M, Lundgren B, Westh H, Mathiesen LR, Ravn P. Latent tuberculosis in HIV positive, diagnosed by the M. tuberculosis specific interferon- $\gamma$ test. Respir Res 2006; 7: 56 .

12 Matulis G, Juni P, Villiger PM, Gadola SD. Detection of latent tuberculosis in immunosuppressed patients with autoimmune diseases: performance of a Mycobacterium tuberculosis antigen-specific IFN- $\gamma$ assay. Ann Rheum Dis 2008; 67: 84-90.

13 Leyten EM, Lin MY, Franken KL, et al. Human T-cell responses to 25 novel antigens encoded by genes of the dormancy regulon of Mycobacterium tuberculosis. Microbes Infect 2006; 8: 2052-2060.

14 Denis M, Wedlock DN, McCarthy AR, et al. Enhancement of the sensitivity of the whole-blood $\gamma$ interferon assay for diagnosis of Mycobacterium bovis infections in cattle. Clin Vaccine Immunol 2007; 14: 1483-1489.

15 Leyten EMS, Arend SM, Prins C, Cobelens FGJ, Ottenhoff THM, van Dissel JT. Discrepancy between Mycobacterium tuberculosis-specific $\gamma$ interferon release assays using short and prolonged in vitro incubation. Clin Vaccine Immunol 2007; 14: 880-885.

16 Hughes AJ, Hutchinson P, Gooding T, Freezer NJ, Holdsworth SR, Johnson PD. Diagnosis of Mycobacterium tuberculosis infection using ESAT-6 and intracellular cytokine cytometry. Clin Exp Immunol 2005; 142: 132-139.

17 Abramo C, Meijgaarden KE, Garcia D, et al. Monokine induced by interferon $\gamma$ and IFN- $\gamma$ response to a fusion 
protein of Mycobacterium tuberculosis ESAT-6 and CFP-10 in Brazilian tuberculosis patients. Microbes Infect 2006; 8: $45-51$.

18 Ulrichs T, Munk ME, Mollenkopf H, et al. Differential T cell responses to Mycobacterium tuberculosis ESAT6 in tuberculosis patients and healthy donors. Eur J Immunol 1998; 28: 3949-3958.

19 Millington KA, Innes JA, Hackforth S, et al. Dynamic relationship between IFN- $\gamma$ and IL-2 profile of Mycobacterium tuberculosis-specific T cells and antigen load. J Immunol 2007; 178: 5217-5226.

20 Ruhwald M, Bjerregaard-Andersen M, Rabna P, Kofoed K, Eugen-Olsen J, Ravn P. IP-10/CXCL10 release is induced by incubation of whole blood from tuberculosis patients with ESAT-6, CFP10 and TB7.7. Microbes Infect 2007; 9: 806-812.

21 Moser B, Loetscher P. Lymphocyte traffic control by chemokines. Nat Immunol 2001; 2: 123-128.

22 Ragno S, Romano M, Howell S, Pappin DJ, Jenner PJ, Colston MJ. Changes in gene expression in macrophages infected with Mycobacterium tuberculosis: a combined transcriptomic and proteomic approach. Immunology 2001; 104: 99-108.

23 Korpi-Steiner NL, Bates ME, Lee WM, Hall DJ, Bertics PJ. Human rhinovirus induces robust IP-10 release by monocytic cells, which is independent of viral replication but linked to type I interferon receptor ligation and STAT1 activation. J Leukoc Biol 2006; 80: 1364-1374.

24 Mezger M, Steffens M, Beyer M, et al. Polymorphisms in the chemokine (C-X-C motif) ligand 10 are associated with invasive aspergillosis after allogeneic stem cell transplantation and influence CXCL10 expression in monocytederived dendritic cells. Blood 2008; 111: 534-536.

25 Van Damme J, Proost P, Put W, et al. Induction of monocyte chemotactic proteins MCP-1 and MCP-2 in human fibroblasts and leukocytes by cytokines and cytokine inducers. Chemical synthesis of MCP-2 and development of a specific RIA. J Immunol 1994; 152: 5495-5502.

26 Dhillon NK, Peng F, Ransohoff RM, Buch S. PDGF synergistically enhances IFN- $\gamma$-induced expression of CXCL10 in blood-derived macrophages: implications for HIV dementia. J Immunol 2007; 179: 2722-2730.

27 Proost P, Wuyts A, Van Damme J. Human monocyte chemotactic proteins-2 and -3: structural and functional comparison with MCP-1. J Leukoc Biol 1996; 59: 67-74.

28 Farber JM. Mig and IP-10: CXC chemokines that target lymphocytes. J Leukoc Biol 1997; 61: 246-257.

29 Azzurri A, Sow OY, Amedei A, et al. IFN- $\gamma$-inducible protein 10 and pentraxin 3 plasma levels are tools for monitoring inflammation and disease activity in Mycobacterium tuberculosis infection. Microbes Infect 2005; 7: 1-8.

30 Juffermans NP, Verbon A, van Deventer SJ, et al. Elevated chemokine concentrations in sera of human immunodeficiency virus (HIV)-seropositive and HIVseronegative patients with tuberculosis: a possible role for mycobacterial lipoarabinomannan. Infect Immun 1999; 67: 4295-4297.

31 Bourgarit A, Carcelain G, Martinez V, et al. Explosion of tuberculin-specific Th1-responses induces immune restoration syndrome in tuberculosis and HIV co-infected patients. AIDS 2006; 20: F1-F7.

32 Okamoto M, Kawabe T, Iwasaki Y, et al. Evaluation of interferon- $\gamma$, interferon- $\gamma$-inducing cytokines, and interferon- $\gamma$-inducible chemokines in tuberculous pleural effusions. J Lab Clin Med 2005; 145: 88-93.

33 Olszyna DP, Prins JM, Dekkers PE, et al. Sequential measurements of chemokines in urosepsis and experimental endotoxemia. J Clin Immunol 1999; 19: 399-405.

34 Qiu B, Frait KA, Reich F, Komuniecki E, Chensue SW. Chemokine expression dynamics in mycobacterial (type-1) and schistosomal (type-2) antigen-elicited pulmonary granuloma formation. Am J Pathol 2001; 158: 1503-1515.

35 Ardigo D, Assimes TL, Fortmann SP, et al. Circulating chemokines accurately identify individuals with clinically significant atherosclerotic heart disease. Physiol Genomics 2007; 31: 402-409.

36 Piper KP, Horlock C, Curnow SJ, et al. CXCL10-CXCR3 interactions play an important role in the pathogenesis of acute graft-versus-host disease in the skin following allogeneic stem-cell transplantation. Blood 2007; 110: 3827-3832.

37 Hori T, Naishiro Y, Sohma H, et al. CCL8 is a potential molecular candidate for the diagnosis of graft versus host disease. Blood 2008; 111: 4403-4412.

38 Zeremski M, Markatou M, Brown QB, Dorante G, Cunningham-Rundles $\mathrm{S}$, Talal AH. Interferon $\gamma$-inducible protein 10: a predictive marker of successful treatment response in hepatitis C virus/HIV-coinfected patients. J Acquir Immune Defic Syndr 2007; 45: 262-268.

39 Samson KTR, Minoguchi K, Tanaka A, et al. Inhibitory effects of fluvastatin on cytokine and chemokine production by peripheral blood mononuclear cells in patients with allergic asthma. Clin Exp Allergy 2006; 36: 475-482.

40 Hanley JA, McNeil BJ. A method of comparing the areas under receiver operating characteristic curves derived from the same cases. Radiology 1983; 148: 839-843.

41 Youden WJ. Index for rating diagnostic tests. Cancer 1950; 3: 32-35.

42 Pai M, Kalantri S, Dheda K. New tools and emerging technologies for the diagnosis of tuberculosis: part I. Latent tuberculosis. Expert Rev Mol Diagn 2006; 6: 413-422.

43 Pai M, Dheda K, Cunningham J, Scano F, O'Brien R. T-cell assays for the diagnosis of latent tuberculosis infection: moving the research agenda forward. Lancet Infect Dis 2007; 7: 428-438.

44 Pai M, Kalantri S, Dheda K. New tools and emerging technologies for the diagnosis of tuberculosis: part II. Active tuberculosis and drug resistance. Expert Rev Mol Diagn 2006; 6: 423-432.

45 Mori T, Sakatani M, Yamagishi F, et al. Specific detection of tuberculosis infection: an interferon- $\gamma$-based assay using new antigens. Am J Respir Crit Care Med 2004; 170: 59-64.

46 Pai M, Menzies D Interferon- $\gamma$ release assays, what is their role in the diagnosis of active tuberculosis? Clin Infect Dis, 2007; 44: 74-77.

47 Arend SM, Thijsen SFT, Leyten EMS, et al. Comparison of two interferon- $\gamma$ assays and tuberculin skin test for tracing 
tuberculosis contacts. Am J Respir Crit Care Med 2007; 175 618-627.

48 Soysal A, Torun T, Efe S, Gencer H, Tahaoglu K, Bakir M. Evaluation of cut-off values of interferon- $\gamma$-based assays in the diagnosis of M. tuberculosis infection. Int J Tuberc Lung Dis 2008; 12: 50-56.
49 Pai M, Joshi R, Dogra S, et al. Serial testing of health care workers for tuberculosis using interferon- $\gamma$ assay. Am J Respir Crit Care Med 2006; 174: 349-355.

50 Weinstein S, Obuchowski NA, Lieber ML. Clinical evaluation of diagnostic tests. AJR Am J Roentgenol 2005; 184: 14-19. 